\title{
Withdrawal of Glucocorticoid Therapy is Difficult in Women with Polymyalgia Rheumatica: An Observational Study
}

\author{
Dai Aoki ${ }^{1,2}$ \\ Nobuyuki Kajiwara (D) 3,4 \\ Keiko Irishio ${ }^{5}$ \\ Yasuhiro Kato iD ${ }^{6}$ \\ Shinya Suezaki \\ Misaki Kageyama' \\ Masahiro Misago' \\ Daisuke Tamai $^{7}$ \\ Shinichiro Nakao \\ Takato Ueoka' \\ Mototoshi Ito' \\ Shinichiro Murakami ${ }^{1,4}$ \\ 'Department of Emergency and General \\ Medicine, Ikeda City Hospital, Ikeda, \\ Osaka, Japan; ${ }^{2}$ Fukuchiyama City Hospital \\ Ooe-Branch, Fukuchiyama, Kyoto, Japan; \\ ${ }^{3}$ Department of Nephrology, Ikeda City \\ Hospital, Ikeda, Osaka, Japan; ${ }^{4}$ Toyono \\ Town National Health Insurance Clinic, \\ Toyono, Osaka, Japan; ${ }^{5}$ Department of \\ Clinical Research, Ikeda City Hospital, \\ Ikeda, Osaka, Japan; ${ }^{6}$ Department of \\ Respiratory Medicine and Clinical \\ Immunology, Graduate School of \\ Medicine, Osaka University, Suita, Osaka, \\ Japan; ${ }^{7}$ Tamai Medical Clinic, Hannan, \\ Osaka, Japan
}

Objective: A total of 105 patients (64 women) who were started on glucocorticoid (GC) treatment for polymyalgia rheumatica (PMR) and/or remitting seronegative symmetrical synovitis with pitting edema $\left(\mathrm{RS}_{3} \mathrm{PE}\right)$ syndrome at Ikeda City Hospital from July 2004 to December 2019 were reviewed (PMR: 81, overlap: 20, pure $\mathrm{RS}_{3} \mathrm{PE}$ syndrome: 4). Then, 32 cases that had stopped GC and 17 cases that had continued GC for 7.5 years or longer were evaluated (women:men, stopped GC 12:20, continued GC 13:4, respectively) (PMR:overlap: pure $\mathrm{RS}_{3} \mathrm{PE}$ syndrome, stopped GC 26:6:0, continued GC 14:2:1, respectively).

Methods: The GC continuation rate in all patients was examined using the Kaplan-Meier method. The following were compared between the two groups: age at starting GC; sex; erythrocyte sedimentation rate, C-reactive protein, hemoglobin, ferritin, aspartate aminotransferase, and alanine aminotransferase before starting GC; days from the onset of symptoms to GC initiation; GC maximum dose; GC dose half a year after its start; presence of relapse; and existence of concomitant malignant disease.

Results: The GC continuation rate 7.5 years after GC initiation was $52.5 \%$, higher in women $(69.2 \%)$, than in men $(27.1 \%)$. The rates then remained unchanged for 15 years. Hemoglobin was high, and relapse was uncommon in the group that stopped GC. There were no differences in other items.

Conclusion: It is difficult to stop GC therapy for PMR in women in Japan, especially in cases with severe anemia.

Keywords: discontinuation of therapy, glucocorticoid, polymyalgia rheumatica, remitting seronegative symmetrical synovitis with pitting edema syndrome, sex difference

\section{Introduction}

Polymyalgia rheumatica (PMR) and remitting seronegative symmetrical synovitis with pitting edema syndrome $\left(\mathrm{RS}_{3} \mathrm{PE}\right.$ syndrome) are diseases of unknown etiology that affect elderly persons. They are characterized by pain of sudden onset that continues and elevated erythrocyte sedimentation rate and C-reactive protein levels. ${ }^{1}$ Once the symptoms develop, they greatly impair patients' quality of life. With the aging of the population, an increase in the number of such patients has been reported from the UK. ${ }^{2}$ The incidence of PMR has been found to be higher in individuals of Scandinavian background, lower in Southern European countries, and unknown in Japan. ${ }^{3,4}$ Although the symptoms improve markedly with glucocorticoid (GC) treatment, prudent tapering of GC is required. ${ }^{5}$ Although GC could be decreased from the initial dose in all PMR patients, it is difficult to stop
Correspondence: Dai Aoki

Department of Emergency and General

Medicine, Ikeda City Hospital, 3-1-18

Johnan, Ikeda, Osaka, 563-8510, Japan

Tel +8I-72-75I-288I

Fax +8I-72-754-6380

Email 1000.0.d5II@gmail.com 
GC treatment, as has been previously reported. ${ }^{6}$ Past studies reported that relapse has been variably associated with female sex, longer duration of morning stiffness, peripheral arthritis, higher erythrocyte sedimentation rate at diagnosis, persistent elevations of C-reactive protein, interleukin-6 levels, and soluble interleukin-6 receptor levels, larger initial doses of prednisone, and a faster rate of tapering. ${ }^{7}$ Furthermore, reports of GC continuation and risk factors for relapse in Japanese PMR patients are few. ${ }^{4}$ To better estimate GC treatment duration, the percentage of patients who could stop GC treatment and the baseline variables associated with inability to withdraw GC after the time when the GC continuation rate stopped decreasing were examined. In particular, sex differences were examined.

\section{Materials and Methods}

A total of 105 patients (64 women) who were started on $\mathrm{GC}$ treatment for PMR and/or $\mathrm{RS}_{3} \mathrm{PE}$ syndrome at Ikeda City Hospital from July 2004 to December 2019 were evaluated. Bird's criteria ${ }^{8}$ were used up to 2014 , and the EULAR/ACR polymyalgia rheumatica interim standard of classification $^{9}$ was used between 2015 and 2019 for PMR diagnosis. Patients who showed pitting edema of both hands and both lower extremities and did not fulfill the diagnostic criteria of rheumatoid arthritis, ${ }^{10}$ spondyloarthropathy, ${ }^{11}$ or other diseases were diagnosed as having $\mathrm{RS}_{3} \mathrm{PE}$ syndrome. Both PMR and $\mathrm{RS}_{3} \mathrm{PE}$ syndrome were diagnosed in patients with PMR who showed pitting edema of both hands and both lower extremities without other cause.

The GC dose was left to the discretion of the attending physician. The initial dose of prednisolone is generally 10 to $16 \mathrm{mg} /$ day, and the aim is to discontinue it by $2-4$ years. The dose was actually reduced by $2.5 \mathrm{mg} /$ day every $2-4$ weeks in patients treated with $>10 \mathrm{mg} /$ day, and by $1 \mathrm{mg} /$ day every $2-4$ weeks in patients treated with $\leq 10 \mathrm{mg} /$ day. $^{7}$ When symptoms returned with GC reduction, the attending physician increased the dose promptly. GC was continued when it was resumed for disease recurrence once it had been stopped.

The days from $\mathrm{GC}$ initiation to $\mathrm{GC}$ withdrawal were calculated. If $\mathrm{GC}$ could not be stopped, the last observation day was used. The GC continuation rate during the observation period was then estimated by the KaplanMeier method, creating Kaplan-Meier curves by sex.

Furthermore, cases that had stopped GC (withdrawal group) and cases that had continued GC for $\geq 7.5$ years (continuation group) were identified, and the following were compared between them: Age at time of starting GC treatment; sex; type (PMR and/or $\mathrm{RS}_{3} \mathrm{PE}$ syndrome); erythrocyte sedimentation rate, C-reactive protein, hemoglobin, ferritin, aspartate aminotransferase, and alanine aminotransferase levels before starting GC; days from onset of symptoms to $\mathrm{GC}$ initiation; $\mathrm{GC}$ maximum dose; $\mathrm{GC}$ dose half a year after it was started; presence of relapse (GC restarting or increasing due to deterioration of symptoms); and the presence of concomitant malignant disease. Cases belonging to neither the withdrawal group nor the continuation group constituted the intermediate group. Patients with malignant diseases were counted when they were diagnosed with them within 6 months since $\mathrm{GC}$ was started for PMR or $\mathrm{RS}_{3} \mathrm{PE}$ syndrome. It was thought that cases in the intermediate group included cases that would be reclassified to the withdrawal group or the continuation group if they were observed for a longer time. It was expected that the parameters associated with GC continuation in the intermediate group would be between those of the withdrawal group and the continuation group and totaled the parameters in the intermediate group.

This survey was based on a chart review, but a telephone poll of patients whose charts could not be reviewed was conducted.

Statistical analyses were performed with IBM SPSS Statistics, version 27. Kaplan-Meier curves were compared using the Log rank test. Comparisons between the withdrawal group and the continuation group were made with Student's $t$-test for independent continuous variables, and the chi-squared test was used to compare categorical data between groups.

\section{Ethics Approval}

This investigation protocol adopted the ethical guidelines of the 1975 Declaration of Helsinki and was approved by the Ikeda City Hospital Ethics Committee (approval number A20010). The data accessed from the medical records were de-identified in this report. Because this report contains no individual person's data, and this investigation was observational and noninterventional, the Ikeda City Hospital Ethics Committee waived the need for patient consent.

\section{Results}

There were 58 cases diagnosed by Bird's criteria, 43 cases diagnosed by the EULAR/ACR polymyalgia rheumatica interim standard of classification, and 4 cases with pure 
$\mathrm{RS}_{3} \mathrm{PE}$ syndrome. There were 32 cases in the withdrawal group and 17 cases in the continuation group.

The dose of GC could be reduced from the initial dose in all patients.

The duration from the onset of symptoms to GC therapy starting was $79.5 \pm 79.6$ days (mean $\pm \mathrm{SD}$ ) in all patients.

The GC continuation rate 7.5 years after starting GC was $52.5 \%$ in all patients, $69.2 \%$ in women, and $27.1 \%$ in men. The rates remained unchanged for 15 years (Figures 1 and 2). The GC continuation rate was significantly higher in women (Log rank test). No patients were prescribed immunosuppressants.

$\mathrm{P}$ values by Student's $t$-test or the chi-squared test are shown in the table for the other survey items, including numbers of cases, with data displayed as mean \pm standard deviation (Table 1). Since there was a case with suspected temporal arteritis at the beginning in the withdrawal group that was treated with prednisolone $50 \mathrm{mg} /$ day, this case was excluded as an abnormal value for the GC maximum dose and the GC dose half a year after its initiation. In the withdrawal group, there were few women $(\mathrm{P}=0.016)$. In all patients, hemoglobin levels (mean $\pm \mathrm{SD}$ ) before starting $\mathrm{GC}$ were lower $(10.5 \pm 1.6 \mathrm{~g} / \mathrm{dL})$ in women than in men $(11.4 \pm 1.8 \mathrm{~g} / \mathrm{dL})(\mathrm{P}=0.014)$. In the withdrawal group, they were $10.9 \pm 1.5 \mathrm{~g} / \mathrm{dL}$ in women and $11.9 \pm 1.6 \mathrm{~g} / \mathrm{dL}$ in men. In the continuation group, they were $10.4 \pm 1.9 \mathrm{~g} / \mathrm{dL}$ in women and $10.0 \pm 2.8 \mathrm{~g} / \mathrm{dL}$ in men. Relapses were fewer in the withdrawal group than in the continuation group ( $\mathrm{P}=0.0003)$.

\section{Discussion}

In this study, the duration of GC treatment for PMR and $\mathrm{RS}_{3} \mathrm{PE}$ syndrome in Japanese patients was longer than in previous reports in English. ${ }^{12}$ GC treatment was needed for a longer time in women than in previous reports, and it was difficult to stop GC treatment in cases with severe anemia.

Although it has been reported that female sex is a risk factor for long-term GC treatment by Narváez et $\mathrm{al}^{13}$ and Cimmino et $\mathrm{al}^{14}{ }^{14}$ there has been no English-language report from Japan. Aoki et al reported the GC treatment duration of Japanese PMR patients, and they found no difference between men and women. ${ }^{12}$ They classified their patients into two groups by whether they had stopped GC therapy as of 24 months. Therefore, their observation period was shorter than in the present study. Two important factors causing sex-based disparities are genetics and sex hormones. ${ }^{15}$ Estrogen enhances B cell differentiation and immunoglobulin production. ${ }^{16}$ Several studies reported an immunosuppressive role of testosterone on different components of the immune system. ${ }^{15}$ Furthermore, the small number of GC receptors or low $\mathrm{GC}$ receptor affinity in woman may have an effect. ${ }^{14}$

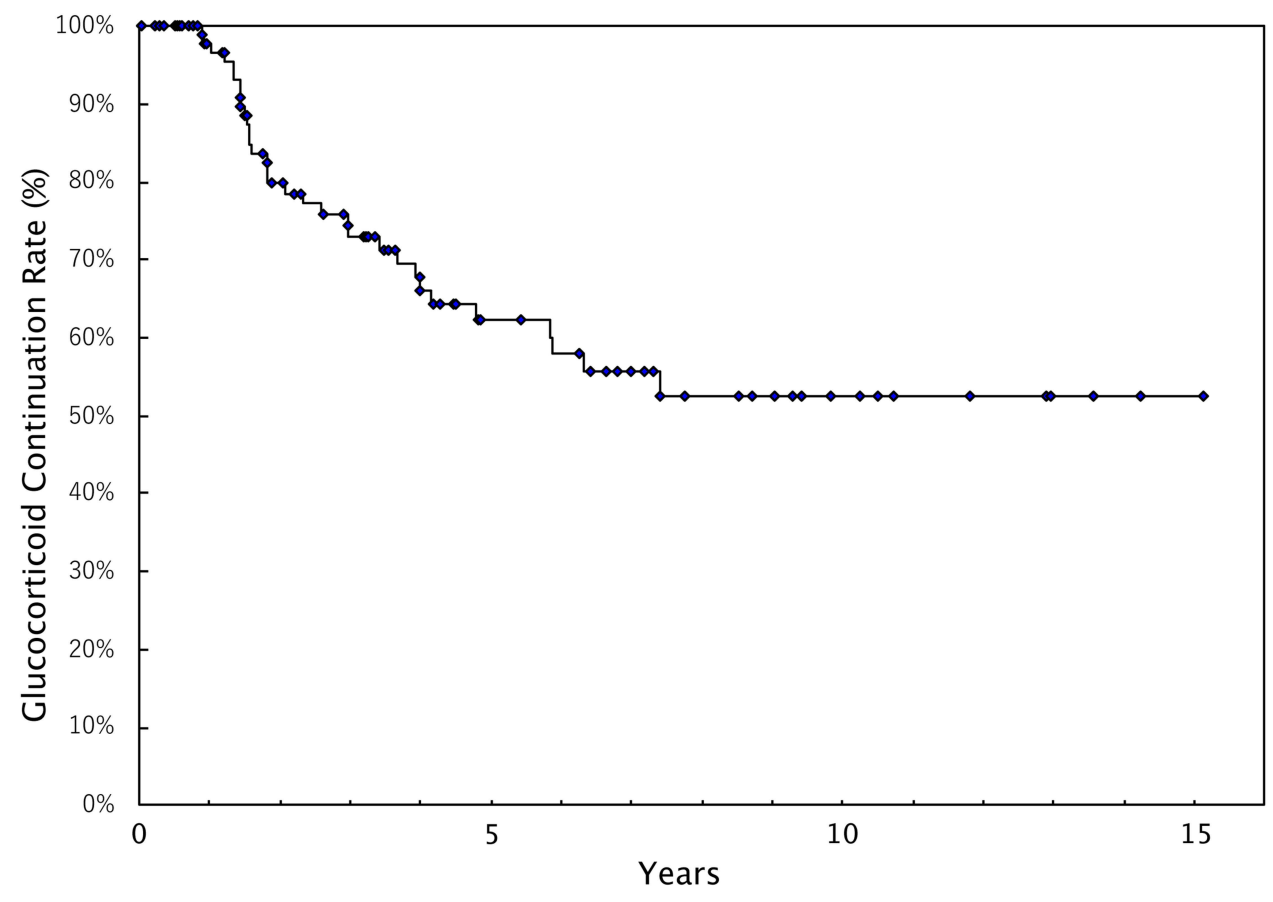

Figure I Glucocorticoid continuation rate of all cases (Kaplan-Meier method). 


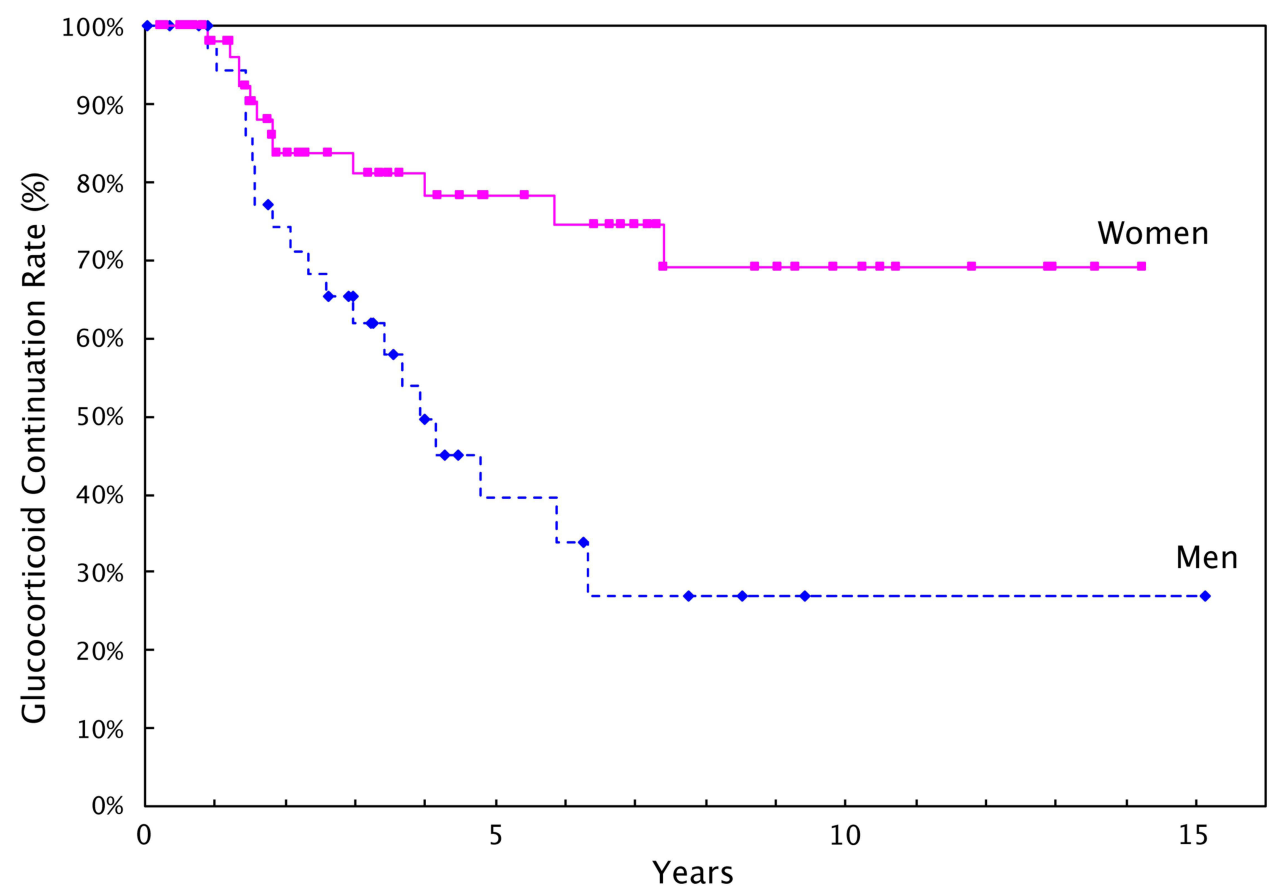

Figure 2 Glucocorticoid continuation rate by sex (Kaplan-Meier method). The glucocorticoid continuation rate is higher in women $(\mathrm{P}=0.020)$.

In the present study, although the GC continuation rate fell to $55.6 \%$ at 7 years and 5 months, it did not fall further. The necessity for continuing GC differed among reports. Aoki et al reported that the median time of remission was 16 months. ${ }^{12}$ Cimmino et al reported that about $26 \%$ of the patients required GC treatment for 6 years or more. ${ }^{14}$ Shbeeb et al reported that the median GC treatment period was 5.95 years. ${ }^{17}$ Although the present study found a longer GC treatment period than previous reports, a prudent approach to $\mathrm{GC}$ dose reduction may have been one reason, given the report of a certain rate of disease recurrence in the report by Aoki et al. ${ }^{12}$ In 17 patients in the continuation group, three patients have not relapsed. This may show that our treatment is sometimes passive with respect to reducing the GC dose. Although there may have been a bias among certain institutions for longer GC treatment, the bias among institutions cannot explain the sex difference. There sometimes were newly suspected patients who received no GC treatment while waiting for spontaneous resolution. This study included no spontaneously resolved patients. The duration from the onset of symptoms to the start of GC therapy in all patients was over 2 months. This might be one reason for the long GC continuation in this study, and it might be a characteristic of Japanese/Asian people.

There are many more female than male patients. In Ikeda City, in which our hospital is located, the population aged 60 years and over as of March 31, 2020, included
18,880 women and 14,506 men. ${ }^{18}$ Therefore, it cannot be said that the incidence is higher among women than men.

Since PMR and the $\mathrm{RS}_{3} \mathrm{PE}$ syndrome often merged, they were considered together in one group. ${ }^{1,19}$ Since there are few pure $\mathrm{RS}_{3} \mathrm{PE}$ syndrome cases, whether there are differences between PMR and $\mathrm{RS}_{3} \mathrm{PE}$ syndrome in GC continuation and by sex is unknown. Aoki et al observed peripheral edema in 41 of 93 PMR patients. ${ }^{12}$ Such cases would be considered combined PMR and $\mathrm{RS}_{3} \mathrm{PE}$ syndrome cases according to the definition used in the present study.

Origuchi et al reported that GC dose and CRP 1 year after starting therapy were high in men with $\mathrm{RS}_{3} \mathrm{PE}$ syndrome. ${ }^{20}$ In the report by Origuchi et al, the observation period was 1 year, shorter than in other reports. ${ }^{20} \mathrm{In}$ the present study, the women's continuation rate was also not high until 1.4 years after starting.

The present data showed severe anemia in the GC continuation group. Narváez et al reported that hemoglobin levels were low in women with PMR. ${ }^{13}$ They considered that anemia reflects intense inflammation. The range of ferritin was large for every case, and the difference between the withdrawal group and the continuation group was not clear. Ferritin levels were high in all groups, reflecting the impaired iron utilization in these diseases.

As a limitation of the present investigation, the number of patients was insufficient for a multivariable statistical 
Table I Clinical Features of the 105 Patients

\begin{tabular}{|c|c|c|c|c|c|}
\hline Characteristic & $\begin{array}{l}\text { Reference } \\
\text { Range, } \\
\text { Adults }\end{array}$ & $\begin{array}{l}\text { Withdrawal } \\
\text { Group }(\mathrm{N}=32)\end{array}$ & $\begin{array}{l}\text { Intermediate } \\
\text { Group }(\mathrm{N}=56)\end{array}$ & $\begin{array}{l}\text { Continuation } \\
\text { Group }(\mathrm{N}=17)\end{array}$ & $\begin{array}{l}\text { P-value* (Withdrawal } \\
\text { Group versus } \\
\text { Continuation Group) }\end{array}$ \\
\hline GC starting age, years & & $73.1 \pm 7.0$ & $76.9 \pm 9.2$ & $71.6 \pm 6.2$ & 0.449 \\
\hline Female sex, no. (\%) & & $12(37.5)$ & $39(69.6)$ & $13(76.5)$ & 0.016 \\
\hline $\begin{array}{l}\text { Type, no. } \\
\text { PMR } \\
\text { PMR and } R S_{3} P E \text { syndrome } \\
\text { Pure } \mathrm{RS}_{3} \mathrm{PE} \text { syndrome }\end{array}$ & & $\begin{array}{c}26 \\
6 \\
0\end{array}$ & $\begin{array}{c}41 \\
12 \\
3\end{array}$ & $\begin{array}{c}14 \\
2 \\
1\end{array}$ & \\
\hline $\begin{array}{l}\text { Duration from the onset of symptoms to GC } \\
\text { therapy starting, days }\end{array}$ & & $78.6 \pm 68.9$ & $75.9 \pm 76.5$ & $93.0 \pm 107.4$ & 0.591 \\
\hline Erythrocyte sedimentation rate, $\mathrm{mm} / \mathrm{hr}$ & $3-15$ & $100.7 \pm 27.1$ & $103.1 \pm 24.5$ & $107.5 \pm 16.8$ & 0.382 \\
\hline C-reactive protein, $\mathrm{mg} /$ liter & $<4.0$ & $70.0 \pm 51.0$ & $87.2 \pm 63.5$ & $81.4 \pm 55.3$ & 0.475 \\
\hline Hemoglobin, g/dL & $12.0-16.0$ & $11.5 \pm 1.6$ & $10.7 \pm 1.5$ & $10.3 \pm 2.0$ & 0.034 \\
\hline Ferritin, $\mathrm{ng} / \mathrm{mL}$ (median) $)^{\pi}$ & $10-200$ & $379.2 \pm 446.7(268)$ & $1047.3 \pm 4351.8(213)$ & $419.3 \pm 398.3(289)$ & 0.772 \\
\hline Aspartate aminotransferase, IU/liter & $10-40$ & $20.6 \pm 11.4$ & $23.5 \pm 4.5$ & $23.1 \pm 10.4$ & 0.452 \\
\hline Alanine aminotransferase, IU/liter & $8-40$ & $24.3 \pm 26.8$ & $20.3 \pm 14.9$ & $20.4 \pm 13.6$ & 0.572 \\
\hline $\begin{array}{l}\text { Dosage of GC (converted to prednisolone) } \\
\text { Maximum dosage, mg/day } \\
\text { Dosage at } 6 \text { months after GC therapy } \\
\text { starting,mg/day }\end{array}$ & & $\begin{array}{l}14.4 \pm 4.2^{1} \\
6.9 \pm 2.1^{1}\end{array}$ & $\begin{array}{l}14.8 \pm 2.9 \\
7.8 \pm 3.1\end{array}$ & $\begin{array}{l}14.2 \pm 3.6 \\
8.1 \pm 3.3\end{array}$ & $\begin{array}{l}0.800 \\
0.144\end{array}$ \\
\hline $\begin{array}{l}\text { Presence of relapse, no. } \\
\text { No relapse } \\
\text { Presence } \\
\text { Unknown }\end{array}$ & & $\begin{array}{c}24 \\
5 \\
3\end{array}$ & $\begin{array}{l}21 \\
18 \\
17\end{array}$ & $\begin{array}{c}3 \\
10 \\
4\end{array}$ & 0.0003 \\
\hline Malignancies, no. & & 2 & 4 & 1 & \\
\hline
\end{tabular}

Notes: Plus-minus values are mean \pm SD. *Comparisons between groups were made using Student's $t$-test and chi-square test. "Because several cases show outliners, medians are shown in parentheses. 'One case with initial diagnosis of giant cell arteritis was excluded.

Abbreviations: GC, glucocorticoid; PMR, polymyalgia rheumatica; $\mathrm{RS}_{3} \mathrm{PE}$, remitting seronegative symmetrical synovitis with pitting edema.

analysis of the GC continuation rate and anemia. In addition, because some of the patients were interviewed by telephone, recall bias may have occurred. Because this study was retrospective, sex hormone levels were not measured before treatment; it is a future task to measure them in order to identify causes of the sex difference.

When considering the future treatment strategy for PMR and $\mathrm{RS}_{3} \mathrm{PE}$ syndrome in Japan, it is important to note that it is difficult to stop GC treatment for women and for those with severe anemia.

\section{Conclusions}

It is difficult to stop GC for PMR and/or $\mathrm{RS}_{3} \mathrm{PE}$ syndrome in women in Japan, especially in cases with severe anemia.

\section{Disclosure}

All authors have no conflicts of interest that should be declared. All authors take full responsibility for the content of this paper.

\section{References}

1. Mimori A. Polymyalgia rheumatica/PMR \& remitting seronegative symmetrical synovitis with pitting edema/RS3PE (in Japanese). In: Mimori A. Physician's Notes on Rheumatology: The Process of Clinical Consideration. 4th ed. Tokyo, Japan: Japan medical journal; 2019:413-426.

2. Partington RJ, Muller S, Helliwell T, Mallen CD, Sultan AA. Incidence, prevalence and treatment burden of polymyalgia rheumatica in the UK over two decades: a population-based study. Ann Rheum Dis. 2018;77(12):1750-1756. doi:10.1136/annrheumdis2018-213883 
3. Gonzalez-Gay MA, Vazquez-Rodriguez TR, Lopez-Diaz MJ, et al. Epidemiology of giant cell arteritis and polymyalgia rheumatica. Arthritis Care Res. 2009;61(10):1454-1461. doi:10.1002/art.24459

4. Nishioka K, Tanaka T. [Rheumatology: Progress in diagnosis and treatments. topics: III. Rheumatoid arthritis and allied conditions; 2. Allied conditions. 2) polymyalgia rheumatica]. Nihon Naika Gakkai Zasshi. 2014;103(10):2440-2448. Japanese. doi:10.2169/ naika. 103.2440

5. Hernández-Rodríguez J, Cid MC, López-Soto A, Espigol-Frigolé G, Bosch X. Treatment of polymyalgia rheumatica: a systematic review. Arch Intern Med. 2009;169(20):1839-1850. doi:10.1001/archintern med.2009.352

6. Muratore F, Pipitone N, Hunder GG, Salvarani C. Discontinuation of therapies in polymyalgia rheumatica and giant cell arteritis. Clin Exp Rheumatol. 2013;31(4 Suppl 78):S86-S92.

7. Docken WP. Treatment of polymyalgia rheumatica [homepage on the Internet]. Wolters Kluwer; 2018 [Updated September 7, 2018]. Available from: https://www.uptodate.com/. Accessed February 21, 2020.

8. Bird H, Esselinckx W, Dixon AS, Mowat A, Wood P. An evaluation of criteria for polymyalgia rheumatica. Ann Rheum Dis. 1979;38 (5):434-439. doi:10.1136/ard.38.5.434

9. Dasgupta B, Cimmino MA, Kremers HM, et al. 2012 provisional classification criteria for polymyalgia rheumatica: a European league against rheumatism/American College of Rheumatology collaborative initiative. Arthritis Rheum. 2012;64(4):943-954. doi:10.1002/ art.34356

10. Arnett FC, Edworthy SM, Bloch DA, et al. The American Rheumatism Association 1987 revised criteria for the classification of rheumatoid arthritis. Arthritis Rheumatism. 1988;31(3):315-324. doi:10.1002/art.1780310302

11. Dougados M, Linden SVD, Juhlin R, et al. The European Spondylarthropathy Study Group preliminary criteria for the classification of spondylarthropathy. Arthritis Rheumatism. 1991;34 (10):1218-1227. doi:10.1002/art.1780341003
12. Aoki A, Kobayashi H, Yamaguchi Y. Predictors of long-term therapy with glucocorticoid in polymyalgia rheumatica. Modern Rheumatol. 2020;31(2):417-426. doi:10.1080/14397595.2020.1777680

13. Narváez J, Nolla-Solé JM, Valverde-García J, Roig-Escofet D. Sex differences in temporal arteritis and polymyalgia rheumatica. J Rheumatol. 2002;29(2):321-325.

14. Cimmino MA, Parodi M, Caporali R, Montecucco C. Is the course of steroid-treated polymyalgia rheumatica more severe in women? Ann N Y Acad Sci. 2006;1069(1):315-321. doi:10.1196/annals.1351.030

15. Trigunaite A, Dimo J, Jørgensen TN. Suppressive effects of androgens on the immune system. Cell Immunol. 2015;294(2):87-94. doi:10.1016/j.cellimm.2015.02.004

16. Moulton VR. Sex hormones in acquired immunity and autoimmune disease. Front Immunol. 2018;9:2279. doi:10.3389/fimmu.201 8.02279

17. Shbeeb I, Challah D, Raheel S, Crowson CS, Matteson EL. Comparable rates of glucocorticoid-associated adverse events in patients with polymyalgia rheumatica and comorbidities in the general population. Arthritis Care Res. 2018;70(4):643-647. doi:10.1002/acr.23320

18. Ikeda City Office [homepage on the Internet]. Populations in Ikeda city by age and sex (in Japanese); April 2, 2020. Available from: http://www.city.ikeda.osaka.jp/material/files/group/4/020331_nenrei betu.pdf. Accessed July 25, 2020.

19. Cantini F, Salvarani C, Olivieri I, et al. Remitting seronegative symmetrical synovitis with pitting oedema (RS3PE) syndrome: a prospective follow up and magnetic resonance imaging study. Ann Rheum Dis. 1999;58(4):230-236. doi:10.1136/ard.58.4.230

20. Origuchi T, Arima K, Umeda M, et al. Clinical outcomes in the first year of remitting seronegative symmetrical synovitis with pitting edema (RS3PE) syndrome. Modern Rheumatol. 2017;27(1):150-154. doi:10.1080/14397595.2016.1192744
International Journal of General Medicine

\section{Publish your work in this journal}

The International Journal of General Medicine is an international, peer-reviewed open-access journal that focuses on general and internal medicine, pathogenesis, epidemiology, diagnosis, monitoring and treatment protocols. The journal is characterized by the rapid reporting of reviews, original research and clinical studies across all disease areas. The manuscript management system is completely online and includes a very quick and fair peer-review system, which is all easy to use. Visit http://www.dovepress.com/ testimonials.php to read real quotes from published authors. 